\title{
Transisi Budaya di Bali dalam Novel Jerman: Wayan zwischen Drogen und Dämonen
}

\author{
Lilawati Kurnia
}

\begin{abstract}
AвSTRACt Europe has been interested in Indonesia for many centuries ago. The Dutch Government and the East-Indies Company (VOC), for example, already established the connection between Indonesian and German along with the colonization when the VOC brought the German Regiment to the islands of Indonesia. Nevertheless, this relationship was not in a friendly way but was the power one. German also adopted the domination of the colony by the Dutch. Bali as the foremost attraction for the Europe since the $19^{\text {th }}$ century has become a place of destination to the western tourists in the $20^{\text {th }}$ century. The transition of Balinese culture and people can be seen in every aspect. The novel Wayan zwischen Drogen und Dämonen shows how the Balinese in mid $20^{\text {th }}$ century is influenced by the western culture and how they survive during the transition from tradition to modernity.
\end{abstract}

KEYWORDS Transisi budaya, pertemuan kebudayaan, novel, stereotipe.

Di dalam khazanah literatur Jerman ternyata terdapat pula novel-novel Jerman yang bertemakan Indonesia. Hal ini disebabkan terjadinya pertemuan dua kebudayaan, Indonesia dan Jerman, yang sudah ada sejak Belanda dahulu menjajah Indonesia. Pertemuan kebudayaan itu, sebagai contoh, dijumpai dalam bidang militer, yaitu saat tentara bayaran Jerman di bawah Kaap Regiment datang dengan VOC dan asal beberapa gubernur jenderal Belanda yang merupakan orang Jerman, seperti von Imhoff. Namun, orang Jerman juga didatangkan untuk bidang ilmu pengetahuan, misalnya Junghuhn; Karl Reinwardt, pendiri Kebun Raya; Georg E. Rümpf-lebih dikenal dengan Rumphius, yang tinggal lama di Ambon dan pakar biologi laut. Di bidang budaya juga diketahui Walter Spies yang tinggal di Bali dan memodifikasi tarian Kecak serta gamelan Bali; demikian pula Max Dauthendey yang meninggal di Malang pada 1918.

Pertemuan kebudayaan Indonesia-Jerman menyebabkan terjadinya penguasaan Barat, dalam hal ini Belanda, terhadap Timur, yaitu Indonesia. Penguasaan didasarkan pada kepentingan ekonomi dan politik, terutama kepentingan ideologi Barat yang ingin meluaskan pengaruhnya. Sejak menemukan jalur menuju daerah penghasil rempah-rempah, Eropa tidak dapat lagi menahan diri untuk tidak menguasai daerah ini. Eropa yang sangat 
memerlukan rempah-rempah tersebut menjadikan Indonesia salah satu koloni dan mengembangkan pasar yang lukratif.

Dalam tulisan ini akan dianalisis proses pertemuan kebudayaan IndonesiaJerman serta dampak yang dibawa serta oleh kedatangan Barat ke Indonesia. Novel Jerman yang menjadi korpus analisis selain menggambarkan transisi budaya di Bali yang diakibatkan oleh kedatangan Barat, dalam hal ini turisturis, ke Timur, juga menggambarkan bagaimana sikap tokoh-tokoh dari kedua budaya itu menyikapi pertemuan kebudayaan itu. Dalam percakapan dan gambaran mengenai Bali dapat diketahui sudut pandang pengarang terhadap proses pertemuan dua budaya itu.

\section{Proses Penanaman Ideologi Barat}

Penguasaan yang didasarkan pada kepentingan ekonomi oleh Barat terhadap Timur disertai dengan penyebaran ideologi yang akan mendukung dan memberikan alasan, baik secara rasional maupun moral untuk tindakannya ini. Ideologi yang diterapkan adalah suatu bentuk penguasaan atas dasar superioritas ${ }^{1}$ atau keunggulan Barat atas Timur. Superioritas itu didasarkan pada suatu teori mengenai stereotipe ${ }^{2}$. Stereotipe dalam hal ini dibatasi sebagai anggapan yang salah mengenai suatu ras, bangsa, atau suku bangsa tertentu. Sikap yang ditunjukkan merupakan hasil penilaian dengan perspektif diri sendiri. The Other atau das Fremde ditinjau melalui kacamata dan kepentingan the Self atau das Eigene. ${ }^{3}$

Stereotipe yang disematkan pada Indonesia atau bangsa Indonesia adalah sikap yang tidak dewasa, kekanak-kanakan, dan naif ${ }^{4}$. Sikap naif ini tidak dapat mengatur diri sendiri, ceroboh, dan selalu bermain-main sehingga dalam tatanan masyarakat maju (dari sudut Barat) tidak dapat diterima. Oleh karena itu, Barat yang dewasa dan sudah maju berkewajiban untuk menjadi "wali" Timur dan sekaligus menjadi "pendidik" Timur. Kewajiban tersebut menjadi beban bagi peradaban Barat karena harus mengubah tatanan tingkah

${ }^{1}$ Of course it is known that the Europeans often considered their culture, in particular their religion and technology, superior to any other culture. The culture of the negroes in Africa were considered lowest, the culture of the Indians in America higher and the culture of Asians highest, but the European culture would stand supreme. In this way, very soon, other peoples were qualified (or rather: disqualified) as less civilized, and as heathe or superstitious. (Paasmann 1993: 6)

${ }^{2}$ Istilah stereotipe diperkenalkan pertama kali oleh jurnalis Amerika, W.Lippmann, pada tahun 1922 untuk menggambarkan pendapat seseorang mengenai kelompok, kelas, pekerjaan, bangsa, dan lain-lain Pendapat itu terbentuk biasanya bukan berasal dari pengalaman diri sendiri melainkan lebih sering merupakan gambaran atau harapan yang sudah ada pada kelompok tertentu atau seseorang. Stereotipe sering didasarkan pada pendapat yang sederhana dan sudah terbentuk, dan sering salah. Walaupun seseorang sudah mempunyai kontak pribadi dengan orang lain atau kelompok lain, stereotipe sering tidak berubah. (Wierlacher 1995: 160)

${ }^{3}$ Teori mengenai das Fremde und das Eigene di Jerman berasal dari Prof. Dr. Alois Wierlacher dan Prof. Dr. Dietrich Krusche, keduanya merupakan pelopor dan pakar Kulturwissenschaften atau Cultural Studies, yang di Jerman juga sering disebut sebagai Interkulturelle Studien.

${ }^{4}$ A further way of distancing a nation temporally is through describing the inhabitants of a country as children; in this way, the people are considered distant from the time of adult Europeans. (Mills 1991: 89) 
laku Timur sekaligus menjadikannya lebih dewasa dan bertanggung jawab. Barat juga menyertakan dalam kampanye itu pranata kehidupan Barat yang akan dijadikan standar di Timur. Bahkan, menurut Robin Winks dan James Rush, beberapa karya sastra dunia turut pula mendukung stereotipe dan prasangka terhadap Timur ini yang hidup terus di dalam dunia pembaca dari generasi ke generasi. ${ }^{5}$

Selain itu, Timur dianggap sebagai kawasan yang belum berbudaya oleh Barat. Bangsa Timur dianggap masih harus diajarkan untuk dapat "duduk" bersama-sama bangsa Barat di dunia internasional. Oleh karena itu, penaklukan daerah-daerah yang dianggap sebagai Timur bukan merupakan suatu eksploitasi melainkan sebagai suatu tugas dan sekaligus keharusan oleh Barat. Hegemoni Barat ditancapkan dalam-dalam pada Timur dengan kekerasan. Bangsa Timur yang tidak mau menerima penaklukan ini kemudian digolongkan ke dalam stereotipe yang buruk, dianggap sebagai bangsa barbar, bahkan sering disebut sebagai bangsa kanibal. ${ }^{6}$

Setelah terjadinya penaklukan oleh Barat yang sudah dimulai pada abad ke-18 sampai awal abad ke-20, hegemoni Barat kembali dikukuhkan dengan adanya serangkaian penanaman ideologi hegemoni ini. Di daerah ataupun negeri mantan jajahan Barat ditanamkan suatu "kesadaran" yang mengharuskan penduduk setempat untuk bergaya hidup bahkan berpikir sesuai dengan kehendak Barat. Mereka yang sudah "terdidik" dalam peradaban Barat ini bahkan tidak lagi menyadari identitas diri sendiri yang telah hilang. Mereka dengan sukarela menyerahkan identitas diri karena merasa rendah diri berhadapan dengan superioritas Barat.

Melalui serangkaian dikotomi yang diperkenalkan dan ditanamkan oleh Barat, seperti beradab dengan tidak beradab, dewasa dengan anak-anak, manusiawi dengan kejam atau bengis, mandiri dengan ketergantungan, hegemoni Barat menjadi sesuatu hal yang ideal, bahkan dianggap sebagai keharusan. ${ }^{7}$ Namun, pada akhir abad ke-20 terlihat adanya suatu pembalikan dari ideologi Barat ini yang dicanangkan oleh Edward Said dalam bukunya Orientalism, yang kemudian diikuti oleh banyak penulis lain seperti Hommi Babbha.

Menurut Babbha, yang berpendapat agak lain dari Said, suatu kombinasi antara dominasi dan kekuasaan tetapi juga hasrat dan kesenangan merupakan

\footnotetext{
${ }^{5}$ Some very great works of literature may support the worst prejudices, whether intentionally or through presistent misapprehensions by generations of readers. (Winks 1990: 5)

${ }^{6} \mathrm{Hulme}$ shows how, within one geographical area, the division civilized/savage was made by Europeans between Arawak and Carib, the Carib were associated with cannibalism, since they resisted colonial rule. (Mills, 1991: 87)

${ }^{7}$ Seorang pakar etnologi Jerman, Urs Bitterli, dalam bukunya Die Wilden und die Zivilisierten menjelaskan dengan rinci bagaimana pertemuan kedua kebudayaan terjadi dan bagaimana kemudian Barat memandang Timur sebagai sesuatu momok sehingga harus ditaklukkan dan juga dikuasai agar tidak menjadi ancaman bagi Barat. Ketidakberdayaan Barat untuk menerima "keanehan" atau "kelainan" budaya Timur telah menjadi motif untuk mendiskriminasi Timur dan mendegradasikannya menjadi setaraf dengan suku-suku bangsa yang liar, barbar, kanibal. Selain itu, motif ekonomi dan politik telah pula mempertajam dipergunakannya stereotipe-stereotipe semacam ini. Dengan demikian, penguasaan Barat atas Timur tidak dapat dihindarkan dan sudah menjadi sesuatu hal yang normal saja.
} 
motif Barat atas Timur. Jenny Sharpe ${ }^{8}$ menyoroti hal ini dengan mengambil contoh India sebagai mantan jajahan Inggris. Ia menunjukkan bahwa sikap ambivalen pada orang Inggris terhadap India memberikan peluang bagi orang India untuk menolak Barat. Identitas hibrida yang dipaksakan dan juga dipakai dengan sukarela oleh sebagian orang India merupakan suatu sikap yang di satu pihak menunjukkan kepasrahan, namun, di pihak lain, merupakan suatu strategi untuk menyikapi kolonialisme Inggris.

Dengan mengacu pada permasalahan tersebut terakhir di atas, dalam tulisan ini saya mencoba menunjukkan hal yang sama dalam novel Jerman Wayan zwischen Drogen und Dämonen (Wayan di antara Narkoba dan Roh Jahat). Di dalam novel bahasan saya ditemukan pula sikap ambivalen yang datang dari pengarang dalam menyikapi problem perubahan budaya di Bali. Hal ini menunjukkan bahwa di balik keinginan untuk tetap menikmati dan memiliki das Fremde terdapat pula suatu sikap yang mengkritik perubahan tersebut.

\section{Das Fremde Versus das Eigene dalam Novel}

Novel Wayan zwischen Drogen und Dämonen menggambarkan situasi dan tradisi di Bali dengan baik dan terperinci. Semua diceritakan melalui Wayan yang kadang-kadang mengingat masa kecilnya di desa. Upacara yang diikuti oleh Wayan sudah dilakukan oleh nenek moyangnya, seperti potong gigi, odalan, dan upacara pembakaran mayat nenek Wayan. Semua gambaran itu memberikan kesan kepada das Eigene, pembaca Jerman, bahwa upacaraupacara tersebut merupakan suatu siklus dalam kehidupan orang Bali.

Penggambaran upacara sangat baik dan dapat memberikan gambaran yang akurat tentang Bali. Melalui bahasa yang dapat dimengerti dengan mudah oleh setiap orang yang berbahasa Jerman, upacara yang sebenarnya rumit dapat digambarkan dengan jelas. Upacara khas Bali ataupun Hindusme merupakan suatu hal yang asing bagi das Eigene ini, namun dialami dengan penuh ketertarikan dan minat besar. Das Fremde atau Timur, dalam hal ini Bali, digambarkan sebagai orang yang hidupnya hanya bergantung pada penyelenggaraan berbagai ragam upacara dan harus menerima semua ini. Das Fremde tidak dapat melepaskan diri dari rangkaian dan siklus upacara ini karena mereka akan dikucilkan dari masyarakat setempat. Hal ini merupakan hukuman yang sangat berat bagi das Fremde/Timur, yang lebih berat daripada hukuman penjara sebagaimana ditunjukkan dalam kutipan terjemahan sebagai berikut.

Mengenai kontak dalam masyarakat kampung juga disinggung oleh sang guru dan ia mengatakannya, "... karena hukuman yang terberat bagi orang Bali bukanlah suatu waktu dalam penjara, melainkan dikucilkannya ia dari masyarakat. Di luar masyarakat ini ia akan bebas tapi ia tidak menginginkannya, karena dalam masyarakat ia mempunyai tempat, mempunyai kewajiban yang harus dipenuhi dan juga mendapatkan hak-haknya." (hlm. 55)

8 "Figures of Colonial Resistence", dalam Post- colonial Studies Reader (1999: 99-103).

${ }^{9}$ Vom Kontakt zur Dorfgemeinschaft spricht auch der Lehrer und sagt abschließend: “... denn die härteste Strafe für einen Balinesen ist nicht ein eventueller Aufenthalt im Gefüngnis, sondern der Ausschluß aus der Gemeinschaft. Außerhalb dieser Gemeinschaft, in der jeder Balinese seinen Platz 
Berdasarkan perkataan itu didapatkan citra das Fremde/Timur sebagai manusia yang tidak dapat melepaskan diri dari hal-hal yang primodial sifatnya. Sementara itu, untuk Barat, yaitu para turis, upacara-upacara ini, walaupun diikuti dengan saksama dan penuh minat, tidak lebih dari sekadar happening yang meriah. Dengan demikian, penggambaran yang sangat akurat pun merupakan suatu usaha agar Barat dapat menikmati upacara-upacara yang bagi Timur merupakan sesuatu yang sakral. Oleh karena itu, dapat dikatakan hubungan antara das Eigene/Barat dan das Fremde/Timur masih dalam tataran subjek dan objek saja walaupun semua hal ini terjadi dan diceritakan belum terlalu lama.

Selanjutnya, diceritakan pula adu ayam yang menjadi kesukaan para pria Bali. Walaupun penggambaran adu ayam ini dilakukan dengan saksama, sikap Barat terhadap tradisi Timur ambivalen. Di satu pihak, Barat terlihat berpihak pada tradisi Timur ini karena dikatakan adu ayam ini bukan sekadar arena berdarah, namun menjadi salah satu dari rangkaian upacara. Tradisi ini dipercaya oleh Timur dapat melunakkan para roh jahat yang haus akan darah sehingga darah yang tertumpah dari ayam-ayam dapat menggantikan korban manusia. Di pihak lain, dari gambaran mengenai adu ayam ini terlihat sikap pengarang yang menganjurkan pelarangan arena adu ayam karena nilai sakral yang semula ada menghilang, dan bahkan hanya menjadi ajang taruhan uang. Modernisasi yang juga melanda Bali ternyata tidak dapat menghapuskan sama sekali tradisi dan kebiasaan ini walaupun nyata-nyata tidak bermanfaat.

Wayan berasal dari keluarga miskin sehingga ibunya harus bekerja keras untuk memenuhi kebutuhan hidup keluarganya. Ia pun harus membantu ibunya di restoran yang dibuka oleh ibunya. Melalui kesibukannya di restoran ini, ia berkenalan dengan tamu-tamu turis dari mancanegara. Selain itu, Bali juga merupakan tempat yang banyak dipakai untuk konferensi dan pertemuan internasional yang membicarakan berbagai isu, mulai dari pariwisata sampai ekonomi, sebagaimana ditampilkan dalam kutipan terjemahan sebagai berikut.

Peristiwa terpenting adalah konperensi negara-negara asia. Konperensi ini adalah untuk memelihara kontak antara negara-negara Asia dengan negara-negara bukan Asia, juga direncanakan perjanjian-perjanjian di bidang budaya dan ekonomi, yaitu pertukaran pemuda-pemudi serta mitra dagang. Wayan pernah juga bermimpi ingin menjadi salah seorang pemuda pertukaran, ketika itu ia masih mempunyai kawan-kawan dari Amerika, Eropa, dan Australia di Kuta. (hlm. 23) ${ }^{10}$

Demikianlah Wayan mempunyai pergaulan yang sudah sangat internasional meskipun standar kehidupannya sendiri jauh dari ini. Dari

hat, seine verschiedenen Aufgaben erfüllt und Rechte genießt, ist er in einem Maße frei, wie es sich niemand wünsch."

${ }^{10}$ Wichtigstes Ereignis: eine internationale Konferenz asiatischer Staaten in einem Luxushotel in Sanur. Kontakte untereinander und zum nicht asiatischen Ausland werden geplant, wirtschaftliche und kulturelle Vereinbarungen zum Austausch von Handelspartnern und Jugendlichen getroffen. Davon hat Wayan auch einmal geträumt, als er noch in Kuta seine Freunde aus Amerika, Europa und Australien hatte. 
teman-teman Barat ini Wayan mendapatkan gambaran tentang standar hidup di negara Barat yang tentu saja lebih tinggi daripada keluarga Wayan ataupun keluarga Bali lainnya. Ia ingin sekali pergi ke negara-negara Barat ini dan ingin mengalami sendiri kebebasan yang tidak ditemuinya di Bali seperti yang tampil dalam kutipan kutipan terjemahan sebagai berikut.

\begin{abstract}
Suatu kali terbang ke sana, tanah air mereka, melihat negara-negara modern dan kota-kota besar. Di sana terdapat mobil-mobil mewah, disko, dan kehidupan yang meriah, selain itu orang dapat bergerak lebih bebas daripada di Bali. Dan sekarang ia masih memikirkannya. Setiap orang di sana mempunyai televisi, sebuah motor atau mobil, sebuah apartemen bagus atau rumah dan banyak uang. Sebagian bahkan mempunyai begitu banyak uang sehingga dapat membeli tiket yang mahal untuk ke Bali dan berlibur dalam hotel-hotel mewah. Ia sudah pernah bekerja di hotel-hotel mewah ini beberapa kali, sehingga ia tahu berapa mahalnya bermalam di situ. Bahkan keluarganya belum tentu dapat menghasilkan uang sebanyak itu dalam sebulan! (hlm.23-24) $)^{11}$
\end{abstract}

Barat memberikan citra Timur yang tertinggal dalam kemajuan zaman karena Timur masih memimpikan barang-barang yang merupakan barang sehari-hari dan dimiliki oleh hampir semua orang di negara-negara Barat. Hal ini ditekankan dengan pemakaian kata modernen Länder (negara-negara modern) sehingga Timur adalah kebalikan dari modern, yaitu terbelakang.

Citra bahwa kehidupan das Eigene yang modern ini memberikan kebebasan dipertegas dengan istilah yang dipakai: flottes Leben (kehidupan yang meriah) dan bewegt man sich viel freier (orang bergerak lebih bebas). Dengan demikian, jelas Timur adalah lawan dari hal-hal tersebut karena masih terkungkung dalam adat istiadat yang sangat kuat. Keadaan ini menyebabkan Wayan (Timur) ingin melepaskan diri dari lingkup budayanya sendiri dan memasuki lingkup budaya Barat meskipun ia mengetahui bahwa hal-hal yang modern ini belum tentu memberikan suatu kebahagiaan yang mantap. Kegamangan Timur terlihat ketika akhirnya ia hanya memakai hasil budaya modern Barat, yaitu narkotika dan kebebasan seksual. Dengan demikian, Wayan atau Timur juga diperlihatkan sebagai bangsa peniru saja karena ia hidup dengan gaya hidup Barat. Ini merupakan kritik dari pengarang terhadap Timur. Kritik ini ditujukan terhadap Timur yang hanya meniru gaya hidup buruk dari Barat.

Kedua hal yang digunakan Wayan tersebut lebih dapat dikatakan sebagai limbah budaya karena hanya akan membawa malapetaka bagi Timur. Karena terlibat penjualan jamur yang menghasilkan halusinasi, Wayan pun terpaksa mendekam dalam penjara dan menghabiskan masa remajanya di tempat itu. Hal itu ditunjukkan dalam kutipan terjemahan sebagai berikut.

${ }^{11}$ Einmal fliegen, weit fort, ihre Heimat, die modernen Länder und großen Städte kennenlernen, wo es tolle Autos, Discos und ein flottes Leben gibt, wo man sich viel freier als hier in Bali bewegen kann! Und auch jetzt gerät er bei diesen Gedanken wieder ins Schwärmen. Jeder hat dort einen Fernseher, en Motorrad oder Auto, eine schöne Wohnung oder ein Haus und viel Geld. Einige haben sogar so viel Geld, daß sie den teuren Flug nach Bali bezahlen können, um dort in den Luxushotels Ferien zu machen. Er hat mehrmals dort gearbeitet und weiß, was eine Übernachtung kostet, mehr als seine Familie den ganzen Monat über zum Leben hat! 
...Wayan dari Puaya berusia lima belas tahun telah menyimpan 270 gram jamur psylocybin, yang dikenal sebagai magic mushroom di losmen Sunrise di Kuta. Losmen ini dipunyai oleh seorang Jerman bersama-sama seorang Indonesia. Wayan menyatakan bahwa seseorang yang tak dikenalnya telah memberikannya, dan ia sama sekali tidak mengetahui akibat narkotis yang dikandungnya. Oleh karena itu ia ingin memberikannya kepada kedua temannya itu, tetapi mereka tidak berada di rumah. ... Cokorda melanjutkan:" Selain itu, terdapat sebuah alinea dalam vonis hukuman yang berbunyi Dengan demikian Wayan dari Puaya tidak dapat dibuktikan telah menjual-belikan narkotika. Walaupun ia menyatakan tidak tahu-menahu tentang akibat narkotis yang diakibatkan jamur tersebut, ia juga menyesali tindakannya serta umurnya yang masih muda telah menyebabkan ia dapat dipengaruhi lingkungannya. Meskipun demikian Wayan tidak dapat dibuktikan sebagai yang tidak bersalah. Oleh karena itu, berdasarkan undang-undang yang dikeluarkan bulan Juli 1984, Wayan dikenakan hukuman enam tahun perjara tanpa percobaan. (hlm. 156-157) ${ }^{12}$

Hal itu dirasakan benar oleh Wayan karena penyesalan yang selalu menghantuinya. Wayan mengetahui bahwa narkotika hanya akan membuat pemakainya menjadi bergantung dan rusak. Ia, yang pada mulanya mengira dapat membebaskan diri dan mendapatkan kepercayaan diri dari narkotika, ternyata malah hancur, yang ditegaskan dalam kutipan terjemahan sebagai berikut.

Waktu itu di Kuta kita berpikir bahwa orang dapat mengembangkan kepercayaan dirinya melalui narkotika. Tapi hal ini adalah suatu kesalahan besar! Aku sendiri belum pernah mencobanya, tapi aku telah banyak melihat pemakainya dan mereka menjadi rusak, hancur dan mengalami depresi. (hlm. 214-215) ${ }^{13}$

Ia tahu telah menyebabkan banyak pemuda hancur dan hal itu disesalinya terlebih-lebih ketika ia diberikan wejangan oleh gurunya di penjara, Ida Bagus, dan oleh Cokorda. Ida Bagus mengingatkan dia akan ajaran agama Hindu yang sudah terlupakan oleh Wayan sebagai berikut.

Apa yang baik atau jahat tidak ditentukan oleh manusia, untunglah demikian. Pedoman yang penting adalah setiap orang hidup tanpa menimbulkan derita pada orang lain, dan, yang kedua, bahwa setiap orang menjaga keharmonisan dengan dunia beserta isinya, baik itu hewan, tumbuh-tumbuhan atau manusia. (hlm. 155)

12 “...wurde der fünfzehn järige Wayan aus Puaya im Losmen 'Sunrise' Kuta, das von einem Balinesen und einem Deutschen gemeinsam bewirtschaftet wird, im Besitz von 270 Gramm psilocybinhaltiger Pilze, allgemein als 'magic mushrooms'bekannt, angetroffen. Er gab an, ein Unbekannter habe ihm di Pilze geschenkt, und er habe sie in Unkenntnis ihrer Drogenwirkung den beiden Freunden bringen wollen, diese aber nicht zu Hause angetroffen' und so weiter." ...Cokorda sagt gerade: "Außerdem gibt es im Gerichtsurteil eine Passage, die lautet: 'So konnte dem Jugendlichen Wayan aus Puaya kein vorsätzlicher Handel mit der Droge nachgewiesen werden. Obwohl er sein Unwissen über die Inhaltsstoffe der Pilze und deren Wirkung wiederholt beteuerte und der Verteidiger auf sein kindlicher Alter und die Verführung durch entsprechende Kreise von verdächtigen Jugendlichen hinwies, konnte eine Unschuld des Angeklagten nicht glaubhaft gemacht werden. Für den nachgewiesenen Besitz der Droge, die per Gesetz vom Juli 1984 allen anderen bekannten Drogen gleichgestellt worden ist, forder der Ankläger sechs Jahre Gefängnis ohne Bewährung' und so weiter.

${ }^{13}$ Damals in Kuta dachten wir immer, man könne Bewußtseinerweiterung durch Drogen erfahren. Doch das ist ein gewaltiger Irrtum! Ich habe es zwar icht selbst probiert, aber ich habe viele Fixer nach dem Drogenkonsum erlebt, kaputt, zerschlagen und deprimiert.

14 "Was nun gut und schlecht ist, das entscheiden Gott sei Dank nicht die Menschen. Eine wichtige Richtlinie aber ist, daß jeder so lebt, daß er keinem anderen Schaden zufügt, und eine zweite, 
Wayan mengingat kembali bahwa ia telah melakukan hal terkutuk itu karena ingin membeli sebuah sepeda motor. Pada kenyataannya, hasil yang diperoleh dari penjualan cukup memadai untuk membeli sebuah sepeda motor walaupun bekas seperti dalam kutipan terjemahan sebagai berikut.

Panen selalu baik dan penghasilan yang didapat selalu dibagi rata di antara mereka. Wayan sering membayangkan kapan ia dapat membeli sebuah sepeda motor, tentu yang bekas saja. (hlm.157) ${ }^{15}$.

Sikap ambivalen pengarang ditunjukkan oleh pemihakan pada Wayan yang menyesal telah meniru begitu saja budaya Barat. Di pihak lain, ditunjukkan pula bahwa Wayan belum dewasa dalam menyikapi benturan budaya, Timur masih terbawa arus dan hanya meniru-niru budaya das Eigene. Melalui kritiknya pengarang menginginkan agar Wayan atau Timur melestarikan kehidupannya yang harmonis. Sementara itu, das Eigene menyayangkan sikap das Fremde yang mengadaptasi kebudayaan Barat dalam hidupnya. Sikap budaya hibrida ini tidak dapat bertahan karena hanya merupakan peniruan saja.

Hal lain yang juga ditiru Wayan adalah kebebasan seksual. Walaupun mencintai Leta, Wayan telah bergaul bebas dengan turis-turis wanita di Pantai Kuta. Bahkan, ia mempunyai hubungan serius dengan Jenny, dan hampir-hampir menghasilkan seorang anak seperti dalam kutipan terjemahan berikut.

Ketika ia sudah berbaring di atas tempat tidur, pikirannya masih berputar-putar di sekitar tema itu. Ia mengingat kembali cintanya kepada Jenny, bagaimana hal-hal yang tidak biasa telah menggairahkannya, dan bagaimana bangganya ia di depan teman-temannya kalau bersama Jenny, dan bagaimana mereka iri kepadanya serta tunduk padanya. Akan tetapi juga, bagaimana sedih dan kecewanya Leta waktu itu. (hlm. 165) ${ }^{16}$

Wayan menyesali hal ini pula ia menyadari bahwa cinta bukanlah sesuatu yang dapat dinikmati sesaat saja.

Mengapa justu kau yang mengalami nasib malang? Aku merasa ikut bersalah. Maafkanlah daku dan jagalah aku selalu di dalam hatimu! (hlm. 210) ${ }^{17}$

Ia akhirnya menyadari bahwa kebahagiaan hanya ditemukan dalam kehidupan berkeluarga, seperti yang dilakukannya dengan Sushila seperti dalam kutipan terjemahan berikut.

daß sich jeder Mensch um die Harmonie mit der Welt und ihrem Inhalt, seien es Tiere, Pflanzen oder Menschen, bemüht.

${ }^{15}$ Die Erträge waren nicht schlecht, und den Verdienst teilten sie immer ehrlich. Wayan überschlug des öfteren, wann er sich endlich ein Motorrad, ein gebrauchtes natürlich, würde leisten können.

${ }^{16} \mathrm{Als}$ er schon lange im Bett liegt,kreisen seine Gedanken noch immer um dieses Thema. Dabei fällt ihm auch wieder seine Liebe zu Jenny ein, wie sehr ihn das Ungewohnte damals gereizt hatte, wie stolz er seinen Freunden gegenüber aufgetreten war, wie sehr sie ihn beneidet und ausgehorcht hatten, aber auch wie traurig und verzweifelt Leta gewesen war

${ }^{17}$ Warum hast gerade Du so ein hartes Schicksal? Auch ich fühl mich mitschuldig daran. Bitte, vergib mir und bahlte mich lieb in Deinem innersten Herzen! 
Upacara penikahan pada sore hari yang dipimpin seorang pedanda, Brahmana Ida Bagus, adalah suatu pengalaman bagi semua orang. Hal ini disebabkan adanya keterikatan dan perasaan mendalam dari orang bijak itu yang diberikan kepada anak didiknya. Wayan sangat berterima kasih dan bahagia. Ia menikmati hari ini yang merupakan hari-hari penuh kehangatan dalam hidupnya karena ia menyadari konsekuensi yang akan mengikuti hal itu. Hangat dan sangat menyenangkan cahaya ini meneranginya di tengah-tengah kegelapan yang berbahaya. Ia lalu memberikan kehangatan ini kepada Sushila yang dirangkulnya. Ia memeluk Sushila dan Bumbol dengan erat, dan dalam kegelapan yang mengelilinginya hati mereka berdetak dengan saksama. (hlm. 234) ${ }^{18}$.

Gambaran citra Timur yang masih hidup dalam keadaan yang terbelakang dan belum tersentuh modernisasi secara keseluruhan diberikan dengan membuat kontras dalam lingkungan penjara. Penjara di sini tidak dilengkapi dengan kecanggihan dan kemajuan Barat. Wayan, yang tidak berhasil melarikan diri, setelah mendapat izin mengikuti palebon neneknya, akhirnya harus kembali ke penjara.

Di sini ia mengalami depresi yang dalam sehingga menjadi seseorang yang sangat pendiam. Cokorda menjelaskan bahwa keadaan ini di negaranegara Barat akan dihindari dengan adanya seorang pakar psikologi yang akan menerapinya.

Ketidakpuasan dalam diri tetap saja ada terutama disebabkan oleh adanya ketidaktenangan yang selalu datang mengganggu. Siang dan malam aku menghantam otakku dengan rasa bersalah dan kebingungan. Cokorda dan pengunjungku yang lain menghiburku, tapi tidak ada gunanya. Aku memaksa diriku untuk menjadi tenang, duduk diam dan menyiksa diri dengan tidak bergerak sedikit pun. Hal ini tidak tanpa efek, aku benar menjadi lebih tenang. Namun bersama dengan ketenangan aku dilingkupi oleh depresi, suatu sikap yang menyerah pada nasib. Ketika Cokorda melihat, bahwa hal ini tidak baik untukku, ia melakukan sesuatu. Ia mendesak adanya suatu peraturan yang baru pada kepala penjara. Ia mendengar bahwa penjara-penjara di luar negeri mempunyai pakar psikologi. Mereka akan mendampingi secara intensif napi muda yang berada dalam krisis. (hlm. 213) ${ }^{19}$

Beruntunglah Wayan masih mempunyai harapan dalam dirinya dan berhasil mengatasi masalahnya dengan berguru pada para pemuka agama. Dalam hal ini, pendapat pengarang yang dikemukakan ke dalam tuturan

${ }^{18}$ Auch die Trauung am Nachmittag durch den Brahmanenpriester Ida Bagus war ein Erlebnis für alle; denn sie zeigte die innere Verbundenheit und Zuneigung des weisen Mannes zu seinem Schützling. Wayan ist dankbar und glücklich. Er genießt diesen Tag auf der Sonnenseite seines Lebens; denn er weiß, daß andere folgen werden, unweigerlich folgen müssen. Warm und wohltuend umfangen ihn die Strahlen des Lichts inmitten drohender Schattten. Und er gibt diese Wärme weiter, indem er seinen Arm um Sushilas Schultern legt. Fest drückter sie und den kleinen Bumbol an sich, und im Gleichklang schlagen ihre herzen in der Dunkelheit, die sie umgibt.

${ }^{19}$ Der innere Unfrieden aber blieb, genährt durch eine ständig nagende Unruhe. Tag und Nacht zermarterte ich mir mein Hirn mit Anklagen und Selbstzweifeln. Auch guter Zuspruch durch Cokorda und andere Besucher half wenig. Ich zwang mich gewaltsam, ruhig zu werden, saß da und kasteite mich mit Bewegungslosigkeit. Das verfehlte nicht ganz seine Wirkung; ich wurde wirklich ruhiger. Zugleich mit der Ruhe aber überkam mich eine alles beherrschende Resignation, eine völlig negative Schicksalsergebenheit. Als Cokorda sah, daß es so nicht mit mir weitergehen konnte, da setzte er alle Hebel in Bewegung, um eine besondere Regelung bei der Gefängnisleitung zu erwirken. Er hatte gehört, daß es in ausländischen Gefängnissen Psychologen gibt, die in Krisenzeiten jugendliche Häftlinge intensiv betreuen. 
ada muatan ideologis yang disamarkan sebagai sudut pandang Barat. Das Eigene/Barat tidak secara langsung mengutarakan pendapatnya. Sementara itu, apabila tuturan tersebut keluar dari tokoh das Fremde/Timur, akan dicapai efek keunggulan das Eigene karena das Fremde sendiri mengakui keunggulan budaya dari Barat. Dengan demikian, das Eigene tidak dapat meninggalkan Weltanschauung yang dipunyainya. Ia masih tetap memandang segala sesuatu dalam lingkup ideologisnya ini walaupun sedang berusaha memasukkan das Fremde menjadi das Eigene.

Di pihak lain, gambaran das Fremde yang ditampilkan dalam sosok Wayan adalah mereka yang gamang dalam menyikapi benturan budaya antara Timur dan Barat. Sementara itu, das Eigene yang datang sebagai turis telah membawa semua hasil produk budayanya dan memberlakukannya pada das Fremde tanpa suatu proses yang memadai. Oleh karena itu, akibat yang timbul adalah suatu penetrasi budaya das Eigene ke dalam budaya das Fremde. Kemudian das Fremde ini oleh das Eigene dimasukkan atau dikooptasi ke dalam das Eigene dengan pengambilalihan semua unsur budaya das Fremde yang dapat dinikmati. Hal ini terlihat dari, misalnya, alam yang belum tersentuh teknik, atau keserasian yang terdapat antara manusia dan alam semestanya, serta banyak lagi hasil budaya das Fremde yang kemudian dinikmati dan diambil alih oleh das Eigene.

Laura, salah seorang kawan Wayan, mempunyai seorang anak hasil hubungan di luar nikah dengan Cokorda Muwana. Meskipun mencintai Muwana, Laura tidak mau menikahinya. Laura tidak ingin meninggalkan pekerjaannya sebagai guru di Inggris, suatu hal yang hanya dilakukan wanita Barat karena wanita Bali akan mengikuti suaminya.

\footnotetext{
“Tapi, hal itu sangat sulit baginya. Apakah kalian tidak ingin menikah atau paling tidak, hidup bersama?" "Ja, di mana? Kau begitu mudah mengatakannya. Aku mempunyai pekerjaan di Inggris sebagai guru dan Muwana adalah pelukis. Tidak seorang pun dari kami ingin meninggalkan eksistensinya. "Kau benar-benar seorang wanita Eropa! Bagi seorang wanita Bali hal ini bukan masalah, karena ia akan mengikuti suaminya. Kalau kau benar-benar mencintai Muwana dan kau akan meninggalkan pekerjaanmu. Di sini kau dapat memberikan les privat, hal ini tidak sulit." (hlm. 141) ${ }^{20}$
}

Gambaran yang diberikan kepada Timur, dalam hal ini wanita Bali, adalah wanita yang permisif. Sementara itu, Barat atau Laura merupakan wanita yang mandiri dan rasional sehingga ia bergeming terhadap perasaan cinta. Walaupun demikian, Laura memikirkan di mana anaknya akan hidup. Ia tidak ingin anaknya menjadi gamang dalam dua budaya.

20 "Das ist allerdings hart für ihn. Wollt ihr denn nicht heiraten oder wenigstens zusammenleben?" "Ja, wo denn? Das stellst du dir so leicht vor. Ich habe meinen Job in England als Lehrerin und Muwana seinen hier als Maler. Keiner möchte seine einigermaßen gesicherte Existenz so schnell aufgeben." "Du bist wahrlich eine Europäerin! Für eine Balinesin wäre das gar keine Frage,ob sie zu ihrem Mann ziehen sollte. Wenn du Muwana wirklich liebstest, würdest du deinen Job aufgeben und hier Privatunterricht erteilen, das ist gar nicht so schwer." 
"Kau benar," kata Laura, "aku harus menentukan agar Sarah tidak menjadi pengembara di antara dunia-dunia." (hlm. 142) ${ }^{21}$

Namun, untuk menikah dengan Muwana, Laura tidak mau. Das Eigene tetap merasa das Fremde sebagai sesuatu yang asing.

"Kami saling mengerti, tapi tidak begitu baik untuk dapat hidup bersama-sama. Walaupun ada ketertarikan terhadap budaya, agama, dan alam, yang sangat mendalam, tapi semua ini merupakan dunia yang asing bagiku. Dapatkah kau mengerti? (hlm.142) ${ }^{22}$.

Dengan demikian, das Eigene hanya melakukan petualangan seksual tanpa ingin suatu keterikatan dengan das Fremde demikian pula dengan budaya das Fremde yang tidak dimengertinya. Laura tidak menginginkan putrinya menjadi das Fremde sehingga ia membawanya ke Inggris agar menjadi bagian dari Barat.

"Muwana dipaksa oleh keluarganya. Mereka ingin mengadopsiSarah dan membesarkannya. Ia harus menjadi Ksatria sejati dan mewarisi gelar kebangsawanannya. Tapi, aku akan kehilangan semua hak-hakku terhadap anakku sesuai dengan peraturan Bali. Aku tak dapat membawanya pulang ke rumah." "Rumahmu-maksudmu pasti Inggris. Jadi itulah rumahmu yang sebenarnya." "Ja, demikianlah. Aku ingin sekali Sarah dibesarkan di Inggris, dan aku akan membawanya sesering mungkin ke sini. Jadi, ia akan dapat menerimanya sebagai tanah air dan Muwana dapat mengikuti perkembangannya. Nanti dia akan dapat menentukan di mana ia ingin hidup." (hlm. 142)

Keinginan das Eigene untuk menikmati dan mengeksploitasi das Fremde terlihat dari usaha Laura. Kedatangan Laura ke Bali selain ingin mempertemukan Sarah dengan Muwana juga dalam rangka bisnis.

"Baiklah", Laura membela diri, "selain itu aku mempunyai beberapa hal yang berhubungan dengan bisnis. Jual-beli berbagai perhiasan dan pakaian. Butik-butik di London pasar yang baik untuk perhiasan dari perak: perak sterling, ukiran-ukiran perak. Semuanya sangat murah. Pakaian yang dilukis dengan tangan atau disulam dengan tangan sangat laku. Barang-barang semacam itu tidak dapat ditemui di Eropa. Kaulihat kan, bagaimana aku dapat menambah uang saku untuk liburanku ini." (hlm. 143) ${ }^{24}$

${ }^{21}$ "Du hast recht", stimmt Laura wieder zu. "Ich muß mich entscheiden, damit Sarah nicht ein Wanderer zwischen den Welten wird."

22 "Wir verstehen uns gut - aber nicht so gut, daß wir ein Leben zusammen verbringen könnten. Trotz der Faszination der Kultur, Religion und Natur, die ich nach wie vor tief empfinde, ist dies hier eine fremde Welt für mich. Kannst du das begreifen?"

23 "Muwana steht uner dem Druck seiner Familie. Die möchte Sarah adoptieren und großziehen. Sie soll eine echte Ksatria werden und den Titel erben. Damit sind mir aber nach balinesischem Gesetz alle Rechte an meinem Kind genommen. Ich kann es nicht mehr mit nach Hause nehmen." "Nach Hause - damit meinst du sicher England. Das ist also dein wahres Zuhause." "Ja, so ist es. Am liebsten möchte ich Sarah in England großziehen und sie, so oft wie möglich, herbringen, damit sie auch diese Welt als Heimat akzeptieren lernt und Muwana ihre Entwicklung miterlebt. Später kann sie ja dann selbst entscheiden, wo sie leben möchte."

24 "Schon gut", wehrt Laura ab, "außerdem habe ich noch einige geschäftliche Dinge hier zu erledigen. Handel mit Schmuck und Kleidern. Londons Boutiquen sind ein guter Absatzmarkt für euren herrlichen Silberschmuck: Sterlingsilber, feinste Granulatarbeit, und das noch zu günstigen Preisen! Bei der Kleidung gehen die handbemalten und gestickten Sachen besonders gut. So etwas gibt es bei uns 
Laura tidak hanya menikmati keindahan alam, budaya Bali, tetapi juga membawa hasil budaya Bali ke negaranya untuk dijual. Dengan membeli barang-barang itu murah dan menjualnya di negaranya dengan harga yang berlipat, ia mendapat laba yang cukup banyak. Dengan demikian, Timur direduksi hanya menjadi komoditas ekspor-impor dan Barat mendapatkan keuntungan yang lebih banyak.

\section{KeSIMPULAN}

Sekilas novel Wayan zwischen Drogen und Dämonen memberikan pengetahuan dan informasi mengenai Bali dan penduduk serta tradisinya sehingga hampir menyerupai buku panduan perjalanan yang dikemas dalam bentuk novel. Namun, dari penggambaran yang dilakukan pengarang, kita dapat menganalisis bahwa pengarang memberikan pendapat dan sekaligus memberikan cermin pandangan Barat (das Eigene) terhadap Timur (das Fremde). Gambaran yang diberikan secara menyeluruh memberikan kontras yang nyata dua budaya ini. Misalnya dikontraskan kedudukan individu dalam agama Hindu-Bali dengan individu di Barat sehingga terlihatlah individu di Timur merupakan satu mata rantai dari serangkaian mata rantai yang membentuk suatu kesatuan masyarakat Bali. Hal ini kurang dimengerti oleh das Eigene karena di dalam masyarakatnya manusia adalah individu yang mempunyai hak-hak pribadi. Jaminan terhadap hak-hak ini sedemikian kuat sehingga tidak ada kekuatan apa pun, bahkan juga tidak sebuah pemerintah, yang dapat merebutnya.

Namun, keseimbangan yang telah diajarkan dan diamalkan Timur (das Fremde) selama ini tidak dapat bertahan lagi karena pengaruh Barat (das Eigene) yang datang dalam bentuk sistem ataupun budaya. Hal ini, misalnya, tampil dalam suatu sistem hukuman dalam negara modern seperti yang dialami Wayan. Dengan adanya hukuman penjara ini, Wayan yang tumbuh dalam budaya Bali merasa tertekan dan mengalami depresi, seperti dalam kutipan terjemahan berikut.

\footnotetext{
"Hal ini didasarkan pada suatu sistem hukum yang berkembang dalam masyarakat kita selama beratus-ratus tahun. Tapi kita juga adalah negara yang modern, yang juga membuka diri pada pengaruh positif sistem hukum dari negara lain. Kita ambil contoh misalnya perbaikan pelaksanaan hukuman yang diputuskan pada tahun 1981.“ (hlm. $52)^{25}$
}

Pengaruh yang lebih besar dirasakan oleh para turis atau Barat adalah pengaruh budaya Timur yang sangat berlainan dengan budayanya. Das Fremde masih hidup dalam prinsip-prinsip agama yang kuat sehingga ia merupakan manusia yang masih utuh. Gambaran yang diberikan kepada das Fremde adalah suatu masyarakat yang sederhana dan masih dekat dengan

überhaupt nicht. Du siehst, so kann ich noch ein wenig meine Urlaubskasse aufbessern."

25 "Das besagt unser uraltes, im Laufe der Jahrhunderte an den Erfordernissen der Gemeinschaft gewachsenes Recht. Aber wir sind ein moderner Staat, der sich auch den positiven Einflüssen anderer Rechtssysteme nicht verschlossen hat. Nehmen wir zum Beispiel die Verbesserungen des Strafvollzugs, die 1981 beschlossen worden sind. Ihr profitiert alle bereits davon 
alam di sekelilingnya. Suatu gambaran yang ideal bagi das Eigene karena ia merindukan situasi dan keadaan murni seperti ini. Meskipun demikian, dengan datangnya das Eigene dan membawa perangkat kebudayaannya, terjadilah benturan budaya.

Benturan budaya ini memang sangat membingungkan Wayan dan kawan-kawannya. Ia tidak siap menerima berbagai bentuk budaya das Eigene. Dalam proses itu, mereka akhirnya hanya meniru. Di pihak lain, das Eigene mendapatkan semua yang diinginkannya dari suatu negeri nun jauh dan masih dalam keadaan murni. Das Eigene mendapatkan alam yang dinikmatinya, budaya yang sangat eksotis, keramahan das Fremde, sebagai suatu pertukaran budaya yang tidak seimbang. Hal ini juga ditimbulkan oleh kemajuan teknik sehingga das Fremde terpaksa memakai hasil teknik, padahal dapat menyebabkan lingkungan hidupnya terganggu, rusak, bahkan hancur.

Lingkungan hidup das Eigene sendiri sudah pernah mengalami kehancuran sehingga das Eigene mencari sesuatu yang masih utuh. Namun, das Eigene bertindak hanya sebagai pelancong yang menikmati saja tanpa ikut menjaga keutuhan ini. Kemajuan, atau yang disebut sebagai modern, dibawa oleh das Eigene dalam bentuk-bentuk ini; demikian pula dengan suatu kehidupan yang menggunakan teknik. Das Fremde ingin pula mengikuti arah modernisasi ini, tetapi tidak mengetahui akibat yang ditimbulkan olehnya. Oleh karena itu, das Fremde terjebak dalam benturan budaya ini dan hanya mengakibatkan dirinya menderita.

Sesuatu yang patut diberi perhatian pada novel ini adalah sikap kritis yang ditunjukkan pengarang melalui gambarannya mengenai Wayan dan Bali. Ia tidak saja mengkritik das Fremde sebagai suatu bangsa yang terkebelakang dan tertinggal dalam abad modern dengan kemajuan-kemajuan teknologinya. Namun, das Eigene, atau pengarang, kritis pula menyikapi semua ini sebagai permasalahan-permasalahan dalam kebudayaannya sendiri (das Eigene).

Sikap kritis terhadap sikap das Fremde yang kebarat-baratan dengan melakukan seks bebas merupakan kritik terhadap diri sendiri. Kritik ini dilakukan karena pada dekade terakhir abad ke-20 ini penyakit AIDS telah menyerang manusia. Demikian pula dengan kemajuan teknologi yang diwakilkan dengan sepeda motor di tengah-tengah keindahan dan keharmonisan alam Bali merupakan kritik terhadap teknologi modern. Barat sudah mengalami sendiri kehancuran lingkungannya akibat eksploitasi alam secara besar-besaran dengan pemakaian teknologi canggih. Sikap ambivalensi yang ditunjukkan oleh pengarang mengungkapkan sikap mendua pengarang terhadap Timur dan hal ini menyebabkan terbukanya celah untuk Timur untuk memulai penolakannya.

Sementara itu, sikap das Eigene terhadap diri Laura yang mementingkan materi merupakan kritik terhadap materialisme yang menjadi tonggak kebudayan das Eigene atau Barat. Sikap materialistis ini merupakan kritik kedua terhadap diri sendiri yang dilakukan pengarang melalui penggambarannya atas Laura. Hal ini kembali menunjukkan sikap ambivalen pengarang dalam 
menyikapi pertemuan kedua budaya ini. Sikap ambivalen itu di satu pihak merupakan kritik yang timbul dari pengalamannya di dunia Timur atau Bali yang kemudian menyadarkan pengarang akan hilangnya rasa "persaudaraan" di Barat. Di pihak lain pengarang tidak lupa untuk menyebutkan superioritas Barat, dalam hal ini melalui gambaran Laura sebagai wanita yang bebas dan mandiri. Laura tidak seperti wanita di Timur yang bergantung sepenuhnya pada suami; ia menentukan garis hidupnya sendiri.

Gaya hidup hibrida yang ditunjukkan oleh Wayan dan kawan-kawannya melalui mimikri atau peniruan merupakan dampak terjadinya pertemuan dua budaya yang tidak seimbang. Barat kembali datang dan menguasai walaupun tanpa tekanan kekerasan melainkan melalui dengan budaya dan teknologi. Kedua hal itu ternyata jauh lebih ampuh daripada senjata atau kekerasan karena dapat dipertahankan dan ditanamkan lebih kuat, sehingga Timur tidak dapat lagi menyadari bahwa dirinya sudah mengadaptasi dan dikooptasi oleh Barat. Hegemoni Barat telah dikukuhkan melalui ideologi yang secara halus dimasukkan melalui budaya dan teknologi.

\section{Daftar Acuan}

Bachmann-Medick, Doris (ed) (1998), Kultur als Text. Die antropologische Wende in der Literaturwissenschaft. Frankfurt/Main: Fischer Taschenbuchverlag.

Bitterli, Urs (1991), Die Wilden und die Ziviliesierten. Grundzüge eines geistes- und kulturgeschichte der europäische überseeischen Begegnung. München: C.H. Beck'sche Vlg.

Gadamer, Hans-Georg (1974), Hermeneutik historische Wörterbuch der Philosophie III, Darmstadt.

Gunther, Christiane C. (1988), Aufbruch nach Asien. Kulturelle Fremde in der deutschen Literatur um 1900. München: Iudicium.

Hotze, Ilona (1988), Wayan Zwischen Drogen und Dämonen. Berlin: Hotze Verlag.

Mills, Sara (1991), Discourse on Difference. An analysis of Women's Travel Writing and Colonialism. London and New York: Routledge.

Seemann, Heinrich (1996), Indonesien in der deutschen Geisteswelt. Von Goethe bis Emil Nolde. Jakarta, Katalis.

_ (2000), Napak Tilas Persahabatan. Hubungan Jerman-Indonesia Abad ke-16 hingga ke-19. Katalog pada pameran dengan judul yang sama. Jakarta: Cipta Loka Caraka.

Wierlacher, Alois (1985), Das Fremde und Das Eigene. München: Iudicium.

Winks, Robin W. dan James R. Rush (1990), Asia in Western Fiction. Manchester: Manchester Univ. Press.

Sumber dari Internet mengenai Metode Interkultural:

Interkulturelle Kompetenz on line, http://www.ikkompetenz.thueringen.de/Institut für interkulturelle Kommunikation. http://www.iik.com

Verband für interkulturelle Arbeit, arbeiten mit Migranten und Flüchtlinge. http://www. paritaet.org/via

Institut für Migrationsforschung und interkulturelle Studien (IMIS) interdiziplinäres und interfakultatives Forschungsinstitut, http://www.imis.uni-osnabrueck.de.

Institut für interkulturelle Didaktik: interkulturelle trainings, cultural diversity management http://www.ikud.de

Http://www.uni-bayreuth.de/departments/intergerm/fach/home.php. 


\section{LAMPIRAN}

\section{Isi Novel WAyan Z Wischen Drogen und DäMONEN}

Novel ini menceritakan riwayat Wayan, seorang pemuda Bali yang sedang menjalani hukuman badan. Wayan menghabiskan hukumannya di penjara karena ia ditangkap polisi ketika mengedarkan sejenis obat bius. Obat bius ini adalah sejenis jamur yang dapat menghasilkan efek halusinasi apabila dimasak sebagai omelete, dan hidangan ini dijual di Kuta kepada pemakai narkotika. Wayan digambarkan sebagai remaja yang hanya meniru kawan-kawannya dari manca negara. Ketika itu usianya barulah empatbelas tahun sehingga ia diperkenankan untuk meneruskan sekolah sampai usia tujuhbelas tahun. Setelah selesai bersekolah, ia harus menjalani tiga tahun dalam penjara di pulau Jawa.

Wayan sangat menderita di penjara Jawa karena ia merasa asing dan tidak mengerti budaya setempat. Sementara itu, ia sangat merindukan suasana khas Bali dengan berbagai perayaan Hindu yang dirayakan bersama-sama dengan seluruh desa. Wayan merasakan kesepian yang amat sangat dan ia hampir-hampir tidak kuat menahan kerinduannya itu. Untunglah karena berkelakuan baik, ia dipindahkan ke Bali sesuatu hal yang dianggapnya sebagai berkah.

Keluarga Wayan termasuk kasta Sudra, kasta terendah dalam budaya Hindu. Oleh karena itu, keadaan sosial-ekonomi keluarga ini tidak baik. Mereka hidup dalam kemiskinan, dan hal ini diperparah dengan kesukaan ayahnya mengadu ayam sehingga menghabiskan uang belanja istrinya. Adik-adik Wayan, yaitu Made dan Nyoman, masih kecil-kecil ketika ia harus meninggalkan keluarganya dan Bali. Ibu Wayan adalah seorang penari yang baik, namun karena kastanya yang rendah, ia terpaksa harus menikah dengan seorang laki-laki dari kasta yang sama. Untuk menghidupi keluarganya, ibu Wayan berjualan nasi rames dan Wayan sering membantunya. Namun, keterampilan dan bakat menari diwariskan kepada Made yang sering pentas bagi turis-turis asing.

Cerita ini memang terjadi di tahun delapan puluhan di Bali yang sudah dipenuhi oleh turis-turis asing, terutama dari Barat, sehingga hal ini mempengaruhi kehidupan orang Bali. Wayan juga sering memperhatikan turis, bahkan kemudian bersahabat dengan mereka. Dari cerita-cerita mereka Wayan mengetahui tentang standar kehidupan di Barat yang sudah sangat tinggi. Oleh karena itu, Wayan sering bermimpi dan menginginkan standar kehidupan yang sama. Ia ingin mempunyai berbagai barang mewah seperti mobil, kulkas, televisi, stereo set, dan lain-lainnya. Keinginannya ini yang telah menyebabkan Wayan mengikuti cara kehidupan turis-turis ini. Ia mulai minum minuman beralkohol, dan juga menggunakan narkotika.

Untuk memenuhi kebutuhan uang, Wayan bekerja sebagai pemandu wisata amatiran di pantai Kuta. Melalui pekerjaannya ini Wayan dapat berkenalan dengan berbagai turis dari mancanegara, termasuk juga turis-turis wanita Barat. Mereka datang tanpa partner ataupun suami, dan menginginkan suatu petualangan seksual dengan pemuda-pemuda setempat. Wayan termasuk di antara pria muda Bali yang kemudian mengikuti gaya hidup ini. Banyak di antara mereka menjadi "simpanan" wanita Barat. Mereka hidup dengan nyaman atas biaya wanita itu dengan pelayanan seksual sebagai imbalan. Wayan juga menjalin hubungan seperti ini dengan Jenny. Hampir-hampir saja hubungan ini menghasilkan seorang anak di luar pernikahan.

Wayan sebenarnya mencintai Leta, gadis Bali yang menjadi temannya sejak kecil. Namun, kenikmatan seksual dari wanita-wanita Barat serta obat-obatan terlarang telah membutakannya dari cinta Leta. Leta juga berasal dari kasta yang sama sehingga kehidupan Leta pun tidak berbeda dengan Wayan. Leta merasa sangat sedih terutama setelah ditinggal Wayan. Sementara itu, Wayan mempercayai Tom, seorang pemuda Amerika, untuk menjaga Leta. Dengan demikian, Leta sangat tergantung pada Tom. Pada akhirnya mereka mempunyai hubungan yang serius dan menghasilkan seorang anak. Tom juga seorang pengedar narkotika sehingga suatu hari ia tertangkap. Oleh karena itu, ia harus menjalani hukuman penjara. Leta terpaksa bekerja menjadi pelayan pada restoran Kartika. Pemilik restoran dan hotel itu, Kartika, adalah seorang germo terselubung. Dengan demikian, Leta pun akhirnya terpaksa melayani turis-turis Barat. Oleh karena desakan orang tuanya Leta dipaksa menikah dengan seorang pria yang jauh lebih tua, dan ia mengikuti suaminya yang ditransmigrasikan ke Sumatra.

Selama Wayan dipenjara ia tidak mengetahui hal ihwal Leta ini. Ketika ia dipindahkan ke 
penjara di Bali, Wayan mendapatkan izin untuk menghadiri palebon neneknya. Oleh karena itu, kesempatan ini dipergunakan untuk mencari Leta, cinta sejatinya. Dalam kesedihannya, Wayan ingin menyusul Leta ke Sumatera. Akan tetapi, untunglah Cokorda seorang tetangganya yang telah dianggap sebagai pamannya menyadarkan Wayan akan kesia-sia tindakannya ini. Ia juga memperlajari dari Cokorda tentang kebijakan dan agama Hindu dengan baik. Selain itu, dari guru agama di penjara Wayan juga mendapatkan pelajaran berharga sehingga ia mendapatkan ketenangan batin dengan mempraktikkan agamanya itu.

Di penjara Bali, Wayan berkenalan dengan kawan-kawan senasibnya, antara lain Manom yang satu sel dengannya. Selain itu, narapidana lainnya adalah Citak bekas seorang perajin emas, dan Alit seorang pelukis berbakat. Manom dipenjara karena menjual buku-buku porno, sedangkan Citak karena membunuh seorang polisi yang hendak memeriksanya. Sementara itu, Alit, yang pada mulanya beragama Kristen karena dibawa ke Tanah Batak ketika kembali ke Bali, mengalami kebingungan. Oleh karena berbeda agama, ia dikucilkan dari masyarakat di desanya. Hal ini memaksanya kembali memeluk Hindu. Namun, seorang pendeta Kristen mencoba membujuknya kembali lagi pada agama Kristen. Karena bingung, ia lalu menyerang pendeta tersebut dan melukainya. Mereka semua bersahabat baik di dalam penjara dan saling tolong menolong, terlebih-lebih Manom yang memang dikenal Wayan sejak kecil di desanya.

Wayan mendapatkan kesempatan untuk keluar sebentar dari penjara agar dapat menghadiri upacara pembakaran mayat neneknya. Hal ini dimungkinkan karena Cokorda menjadi jaminan baginya. Wayan sangat mencintai neneknya dan ia telah mengukir sebuah topeng khusus bagi neneknya. Di luar penjara Wayan langsung berusaha menghubungi Leta, namun tidak dapat ditemukannya.

Setelah menghadiri upacara pelebon, Wayan tinggal beberapa waktu lagi di penjara, sedangkan Manom sudah dibebaskan. Oleh karena kelakuannya yang baik dan menjadi teladan, Wayan mendapatkan potongan hukuman. Ia kemudian kembali ke keluarganya di desa dan menjalankan kehidupan normal. Ibunya tetap berjualan nasi rames, dibantu oleh seorang wanita bernama Sushila. Sushila sudah mempunyai anak dari hasil hubungannya dengan seorang turis Barat. Sementara itu, turis tersebut meninggalkan Sushila dan tidak datang lagi ke Bali. Dengan demikian, Sushila harus membiayai sendiri hidupnya bersama anaknya itu. Wayan mulai merasa tertarik pada Sushila dan menyayangi anaknya itu. Hal ini disambut oleh Sushila dengan baik. Pada akhirnya Wayan dapat melupakan Leta, cinta pertamanya, dan menikah dengan Sushila. 